\title{
Editorial
}

\section{EL MICROSCOPIO OPERATORIO EN ENDODONCIA}

The operating microscope in Endodontics

Hace mucho tiempo que el hombre busca la magnificación a través de medios artificiales, para mejorar sus condiciones visuales y consecuentemente perfeccionar sus actividades cotidianas y profesionales. Este cuadro viene siendo mejorado con las modificaciones de la iluminación, posición del profesional y con la utilización de lupas y lentes de aumento, las lámparas frontales, así como del Microscopio Operatorio $(\mathrm{MO})^{1}$. El MO permite distinguir detalles que van más allá de la resolución del ojo humano, posee una magnificación que varía de acuerdo al fabricante, de 4X, 6,3X, 10X, 12X, 16X, 20X, 24X hasta 40X.

Los primeros relatos encontrados en la literatura sobre su aplicación en endodoncia quirúrgica y no quirúrgica son de autoría de dentistas y endodoncistas europeos y americanos, entre ellos Baumann, Apotheker \& Jako, Selden, Bellizz, Carr, Pecora, a fines de los 70, cuando estos autores preconizaban las ventajas de la iluminación y magnificación del campo operatório en la tentativa de resolver de forma fácil y confiable casos que sin él no podría resolver ${ }^{1}$.

Hay muchos tipos y marcas comerciales de MO, pero todas tienen en común la visión estereoscópica, la iluminación coaxial y un dispositivo de fijación estable, que mejoran la capacidad diagnóstica y se posibilita una mayor facilidad para trabajar. Existen desde los más sencillos con tres pasos fijos de aumentos y una movilidad estándar regulada por frenos de fricción hasta los que tienen un zoom progresivo motorizado con plena movilidad y estabilizador magnético ${ }^{2}$.

Entre los beneficios en la incorporación del MO en la práctica clínica, podemos citar la magnificación, Iluminación, documentación y ergonomía, que asociadas a la utilización de nuevos equipamientos como ultrasonido, localizadores electrónicos, sistemas de instrumentación mecanizada y a las técnicas de plastificación térmica y adhesivas de obturación, están, revolucionando la Endodoncia en estos últimos ańos, transformando las complicaciones endodónticas en procedimientos más previsibles y de mejor pronóstico permitiendo mayor sobrevida a dientes comprometidos a causa de accidentes, principalmente accidentes iatrogénicos. El empleo del MO no cambia las técnicas endodóncicas del operador, pero sin embargo aporta una precisión en las mismas que facilitan el objetivo de la excelencia en la terapéutica endodóntica².

La popularidad del MO ha alcanzado tal punto que las compañías están fabricando líneas completas de instrumentos y actualmente existe mucho material adaptado para la microendodoncia como microespejos, insertos para ultrasonidos para eliminar calcificaciones, recuperar instrumentos rotos, microcirugía y demás material accesorio como portamateriales diminutos ${ }^{2}$.

Como desventajas, se podría mencionar que los MO tienen precios elevados y un período de adaptación para su manejo que se prolonga de ocho meses a un año ${ }^{2}$.

Otras áreas ${ }^{1}$ en las que la utilización del MO tiene ventajas son: educación del paciente por medio de vídeo, informes clínicos para los dentistas referidores, informes para las compañías aseguradoras o informes de implicación legal, videotecas de documentación para programas de enseñanza o valoración y revisión de la técnica quirúrgica empleadas, empleo de menos radiografías (ya que al mejorar ostensiblemente el diagnóstico en el campo de la endodoncia, se puede conseguir una disminución del uso de otras técnicas de diagnóstico convencionales como el radiodiagnóstico) y menor estrés ocupacional, físico o postural.

Por ello hay que considerar el MO un instrumento inestimable en el ejercicio de la Endodoncia actual.

Mg. Martha Elena Pineda Mejía

Directora de la Revista

ODONTOLOGÍA SANMARQUINA 